\title{
LEACHING KINETICS OF IZOMER TT GLASS FIBROUS INSULATION
}

\author{
JANA VOKELOVÁ*, JAROSLAVA MICHÁLKOVÁ*, MÁRIA CHROMČÍKOVÁ**, ***, \\ BRANISLAV HRUŠKKA****, "MAREK LIŠKA ${ }^{* *}, * * *$ \\ *FunGlass, A. Dubcek University of Trenčín, Študentská 2, SK-911 50 Trenčín, Slovakia \\ **VILA - Joined Glass Centre of the IIC SAS, TnUAD, FChPT STU, Študentská 2, SK-911 50 Trenčin, Slovakia \\ ***VILA, FunGlass, A. Dubcek University of Trenčin, Študentská 2, SK-911 50 Trenčin, Slovakia \\ ****Central Laboratories, FunGlass, Alexander Dubček University of Trenčín, Študentská 2, SK-911 50 Trenčin, Slovakia \\ "E-mail: marek.liska@tnuni.sk
}

Submitted March 16, 2019; accepted May 21, 2019

\begin{abstract}
Keywords: Glass corrosion, LOCA, Glass fibrous insulation, Leaching kinetics
Chemical durability of glass with the composition of glass fibrous insulation IZOMER TT commonly used in nuclear power plants reactor containment was tested by static leaching tests at $70^{\circ} \mathrm{C}, 80^{\circ} \mathrm{C}$, and $90^{\circ} \mathrm{C}$. Distilled water and borate coolant solution were used as corrosive media. The semiempirical kinetic model based on the Aagaard Helgeson kinetic equation was proposed and qualified. Proposed model enables prediction of glass dissolution kinetics for various time-temperature schedules proposed for different Loss of Coolant Accident scenarios.
\end{abstract}

\section{INTRODUCTION}

Large amounts of glass fibers are used as thermal insulation in nuclear power plants (NPPs). In the event of a loss of coolant accident (LOCA) [1-4] the insulation is mechanically destroyed by steam impact and drops to the bottom of the reactor containment, where it is immersed in the alkaline coolant liquid. According to alkali resistance of the commercially produced thermal fibrous insulations glass dissolution occurs, followed by later re-precipitation from the over-saturated solutions [5]. A fraction of the fibers is also captured on the sump screen and thus prevents recirculation of the coolant in the emergency cooling system. Since the partially dissolved fibers can be mechanically destroyed (crushed), they can block the strainer causing failure of the emergency cooling system. In this situation the high head loss reaches a value that disables the operation of the pumps. The above effect of strainer blocking can be dramatically enhanced by strengthening of the fiber bed by the reprecipitated matter. Therefore study of the kinetics and thermodynamics of glass dissolution is needed for correct modeling of the process and its consequences on the operability of the emergency systems. Our previous work was therefore concentrated on leaching of various kinds of commonly used glass fibrous insulation in distilled water and in various coolant solutions used in NPPs [5-8]. Due to the commonly meet irregular shape and broad fiber diameter distribution of various glass fibrous insulations the isothermal static leaching tests are in the first step performed on glass grains with narrow diameter distribution and with the same composition as the studied glass fibrous insulation. The distilled water and the particular coolant solution are used as the leaching solution. The main aim is to develop the reliable kinetic model enabling the qualified prediction of glass dissolution kinetics for various non-isothermal time-temperature regimes proposed for different LOCA scenarios. Therefore, the aim of the present work is the study of the leaching kinetics of IZOMER TT glass fibers used in NPPs. This glass fibrous insulation is produced by Termotechna, a.s. Bratislava (www.termotechna.sk).

\section{THEORETICAL PART}

The time evolution of the chemical composition of leaching solution is represented by the leached amount of each element related to the weight of the leached fibers - so called normalized leached amount, $\mathrm{NL}_{\mathrm{i}}(t)$, of the element $i$ at the time $t$. This quantity is expressed by the equivalent weight of glass containing the same amount of element $i$ as the leaching solution. When a congruent dissolution of glass takes place without any precipitation of dissolved matter, the same value of the normalized leached amount is obtained for each element.

The normalized leached amounts were calculated from the leaching solution composition by:

$$
N L_{i}^{\text {exp }}(t)=\frac{c_{i}(t) V}{w_{i} m}
$$

where $c_{i}(t)\left[\mathrm{mg} \cdot \mathrm{dm}^{-3}\right]$ is the concentration of the $i$-th element in the sample of leaching solution taken at the time $t, V\left[\mathrm{dm}^{3}\right]$ is the volume of the leaching solution, $\mathrm{w}_{\mathrm{i}}$ represents the weight fraction of $i$-th element in the native glass, and $\mathrm{m}[\mathrm{g}]$ is the initial weight of the glass sample. 
The variance of experimental $N L_{i}^{\text {exp }}$ values was evaluated using the three parallel experiments:

$$
s^{2}\left[N L_{i}^{\exp }(t)\right]=\left[\frac{V}{w_{i} m}\right]^{2} s^{2}\left[c_{i}(t)\right]
$$

The Helebrant's empirical kinetic equation was used for smoothing of the experimental $N L_{i}^{\exp }$ data $[9,10]$ :

$$
N L_{i}(t)=P_{A, i}\left[1-\exp \left(-P_{B, i} t\right)\right]
$$

where $P_{A, i}$, and $P_{B, i}\left(P_{A, i}, P_{B, i}>0\right)$ are parameters obtained by minimizing the sum of squares of deviations between the experimental and smoothed $N L_{i}$ values. The reciprocal values of $N L_{i}^{\exp }$ variances (Equation 2) were used as weights in the minimized sum of squares. Using the nonlinear regression analysis the estimates of $P_{A}$, and $P_{B}$ were obtained together with their standard deviations $s\left(P_{A}\right)$, and $s\left(P_{B}\right)$, and covariance $\operatorname{cov}\left(P_{A}, P_{B}\right)$.

The standard deviations of the smoothed $\mathrm{NL}_{\mathrm{i}}$ values were calculated from:

$$
\begin{aligned}
& s^{2}\left[N L_{i}(t)\right]=s^{2}\left(P_{A, i}\right)\left[1-\exp \left(-P_{B, i} t\right)\right]^{2}+ \\
& +s^{2}\left(P_{B, i}\right) P_{A, i}^{2} t^{2} \exp \left(-2 P_{B, i} t\right)+2 \operatorname{cov}\left(P_{A, i}, P_{B, i}\right) \\
& {\left[1-\exp \left(-P_{B, i} t\right)\right] P_{A, i} t \exp \left(-P_{B, i} t\right)}
\end{aligned}
$$

The $95 \%$ confidence interval was then estimated as $N L_{i}(t) \pm 1.96 s\left[N L_{i}(t)\right]$.

The semiempirical kinetic equation derived from the Aagaard Helgeson kinetic equation [11-14] was used for regression analysis of smoothed experimental data:

$$
N R(t, T)=\left(\frac{\partial N L(t)}{\partial t}\right)_{T}=k_{i}(T)\left(1-\frac{\prod_{j}\left[c_{j}(t)\right]^{\alpha_{j}}}{K(T)}\right)
$$

where $N R$ is the normalized leaching rate, $T$ is the thermodynamic temperature, and $j$ denotes the elements taken into account ( $\mathrm{Ca}, \mathrm{B}, \mathrm{Al}, \mathrm{Si})$. Constant values of $a_{j}$ were taken from the stoichiometric glass composition. This model in fact represents the congruent glass dissolution. The Arrhenian temperature dependence of the rate constant, $k$, and the formal solubility product, $K$, was considered:

$$
\ln k=a-b / T \quad \text { and } \quad \ln K=A-B / T
$$

The normalized leached amount $N L(t)$ can be evaluated by the numerical integration of the Equation 6:

$$
N L(t+\Delta t)=N L(t)+N R(t, T(t)) \Delta t
$$

The values of concentrations $c_{j}(t)$ needed for the $N R$ evaluation (Equation 5) are during the numerical integration evaluated from $N L$ values by:

$$
c_{i}(t)=c_{i}(0)+w_{i} m N L(t)
$$

where $c_{i}(0)$ is the concentration of the element $i$ at the beginning of leaching experiment. Thus it is zero for all elements in case of leaching in distilled water and for leaching in coolant solution only the boron concentration is non-zero, i.e. in our case $c_{\mathrm{B}}(0)=1.6485 \mathrm{~g} \cdot \mathrm{dm}^{-3}$.

In the first step, the values of $k(T)$, and $K(T)$ were evaluated from isothermal leaching tests performed at $70{ }^{\circ} \mathrm{C}, 80{ }^{\circ} \mathrm{C}$, and $90{ }^{\circ} \mathrm{C}$. From obtained temperature dependences the starting estimates of $a, b, A$, and $B$ were evaluated from logarithmic plots of $K$ and $k$ versus reciprocal thermodynamic temperature. After that these parameters were optimized by minimizing the sum of squares of deviations between $N L(t)$ and experimental smoothed values $N L_{i}(t)$ :

$$
S(a, b, A, B)=\sum_{k=1}^{3} \sum_{j=1}^{21} \sum_{i}\left[N L\left(t_{j}, T_{k}\right)-N L_{i}\left(t_{j}, T_{k}\right)\right]^{2}=\min .
$$

where $T_{1}=70^{\circ} \mathrm{C}, T_{2}=80{ }^{\circ} \mathrm{C}$, and $T_{3}=90^{\circ} \mathrm{C}$. The samples of leaching solution were analyzed at 21 times $t_{j}$, and $i$ denotes the elements taken into account, i.e. Al, B, and Si in distilled water and $\mathrm{Al}$, and $\mathrm{Si}$ in the coolant solution. Calcium was not included because of its significantly higher $N L$ values caused by the diffusion mechanism of its leaching.

\section{EXPERIMENTAL}

The composition of IZOMER TT glass fibers was determined by X-Ray fluorescence spectroscopy (BRUKER, Tiger S8) using pellets prepared by melting the glass with $\mathrm{Li}_{2} \mathrm{~B}_{4} \mathrm{O}_{7}$. The boron content was measured using the samples in the form of tablets prepared by pressing of the powdered glass. The resulting glass composition is summarized in Table 1.

The glass was prepared by laboratory melting. Glass batch was prepared from analytical purity carbonates and oxides. Glass was melted in platinum-rhodium crucible in superkanthal furnace at temperature $1550{ }^{\circ} \mathrm{C}$ during 2 hours. The homogeneity was ensured by repeated hand mixing of the melt. The glass melt was then poured out onto a stainless steel plate. The glass was tempered in a muffle furnace for one hour at $650{ }^{\circ} \mathrm{C}$, after which the furnace was switched off and samples allowed remain there until completely cool. The glass composition (Table 1) was checked by X-ray fluorescence spectroscopy (Bruker, Tiger S8). Glass grains with the particle size in the range of $(0.500-0.315) \mathrm{mm}$ were prepared by sieving of the milled glass (ČSN ISO 719). The glass composition expressed in mol. \% of oxides is: $25.48 \%$ $\mathrm{CaO}, 7.06 \% \mathrm{~B}_{2} \mathrm{O}_{3}, 8.73 \% \mathrm{Al}_{2} \mathrm{O}_{3}$, and $58.74 \% \mathrm{SiO}_{2}$.

Table 1. Composition (weight \%) of IZOMER TT fibers (only the main components are reported) and laboratory melted glass.

\begin{tabular}{lcccr}
\hline Oxide & $\mathrm{CaO}$ & $\mathrm{B}_{2} \mathrm{O}_{3}$ & $\mathrm{Al}_{2} \mathrm{O}_{3}$ & $\mathrm{SiO}_{2}$ \\
\hline Fibers & $22.54 \pm 0.30$ & $7.75 \pm 0.14$ & $14.04 \pm 0.11$ & $55.67 \pm 0.61$ \\
Glass & $23.35 \pm 0.01$ & $7.05 \pm 0.03$ & $14.08 \pm 0.06$ & $55.52 \pm 0.07$ \\
\hline
\end{tabular}


Such way the following stoichiometric formula of glass was obtained: $\mathrm{Ca}_{0.2548} \mathrm{~B}_{0.1411} \mathrm{Al}_{0.1746} \mathrm{Si}_{0.5874} \mathrm{O}_{1.9031}$. The stoichiometric coefficients were used in the Equation 5, i.e. $\left\{\alpha_{\mathrm{Ca}}, \alpha_{\mathrm{B}}, \alpha_{\mathrm{Al}}, a_{\mathrm{Si}}\right\} \equiv\{0.2548,0.1411,0.1746,0.5874\}$.

Optical emission spectroscopy with inductively coupled plasma (ICP OES - VARIAN - Vista MPX) was used for the analysis of the leaching solutions. Each solution sample was stabilized with nitric acid to achieve $\mathrm{pH}<2$ before the samples were analyzed by ICP OES.

The composition of borate coolant solution prepared from analytical grade purity chemicals was $2.99 \mathrm{~g} \cdot \mathrm{dm}^{-}$ ${ }^{3} \mathrm{KOH}$, and $9.36 \mathrm{~g} \cdot \mathrm{dm}^{-3} \mathrm{H}_{3} \mathrm{BO}_{3}$. The amount of boron leached from glass grains was determined for leaching tests realized in distilled water only. In case of coolant solution this quantity was overwhelmed by the high constant concentration of $\mathrm{H}_{3} \mathrm{BO}_{3}$.

The isothermal static leaching tests of glass grains in distilled water and coolant solution were performed at $70{ }^{\circ} \mathrm{C}, 80{ }^{\circ} \mathrm{C}$, and $90{ }^{\circ} \mathrm{C}$. Approximately $2 \mathrm{~g}$ of glass grains (weighted with the accuracy of $0.01 \mathrm{mg}$ ) were

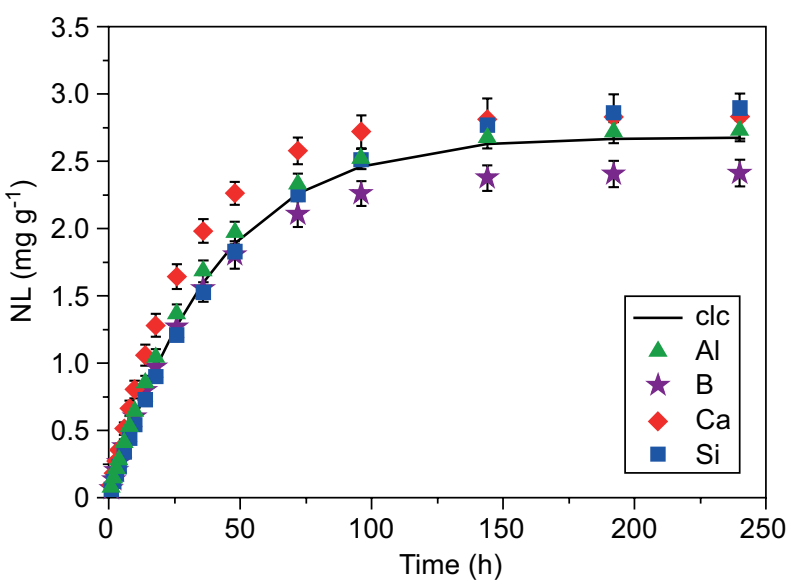

Figure 1. Static leaching test in distilled water at $90{ }^{\circ} \mathrm{C}$ (points - experimental values with error bars, line - calculated $N L$ values).

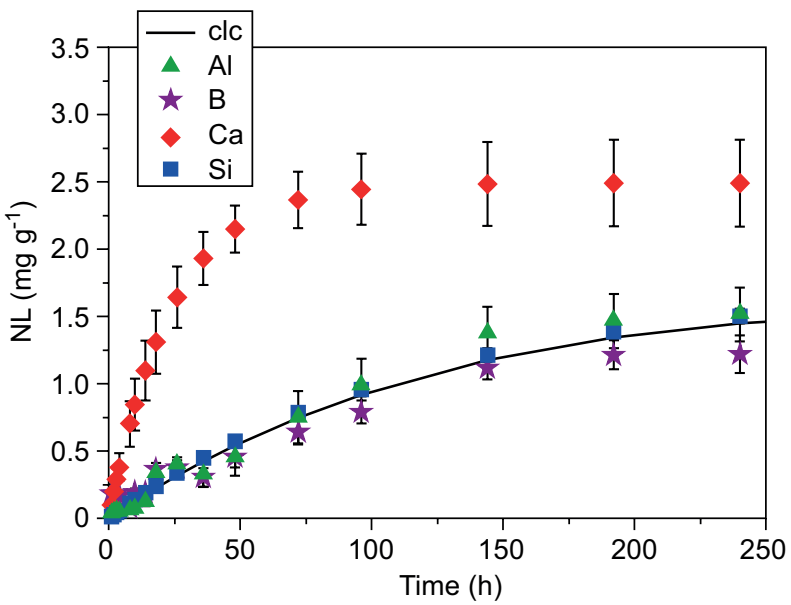

Figure 2. Static leaching test in distilled water at $70{ }^{\circ} \mathrm{C}$ (points - experimental values with error bars, line - calculated $N L$ values). leached in $100 \mathrm{ml}$ of distilled water or coolant solution in polypropylene bottles with screwed caps. The stirring of the solution during the leaching tests was ensured by placing the polypropylene bottles into the gently waging thermostatic bath. The duration of static leaching tests was 30 days. The sampling of leaching solution was performed 21 times at $t_{j} \equiv(1,2,3,4,6,8,10,14,18,26$, $36,48,72,96,144,192,240,336,524,624,720)$ hours by removing the bottle from thermostatic bath. Thus for three parallel experiments the number of samples used was three times the number of sampling times.

\section{RESULTS AND DISCUSSION}

Proposed semiempirical kinetic equation was first qualified by the analysis of the glass grains leaching in distilled water. By minimization of the sum of squares (Equation 9) following estimates of optimized parameters were obtained: $a=(24.01 \pm 0.21), b=(9728 \pm 76)$,

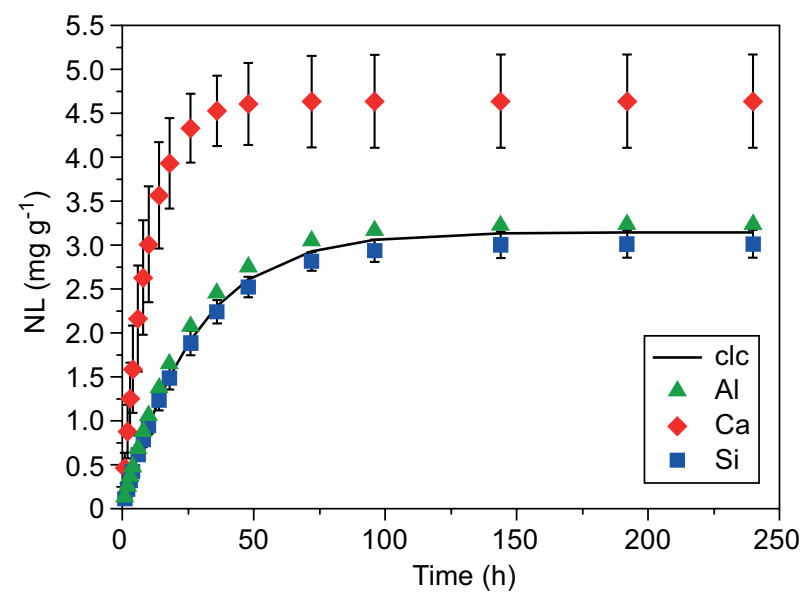

Figure 3. Static leaching test in coolant solution at $90{ }^{\circ} \mathrm{C}$ (points - experimental values with error bars, line - calculated $N L$ values).

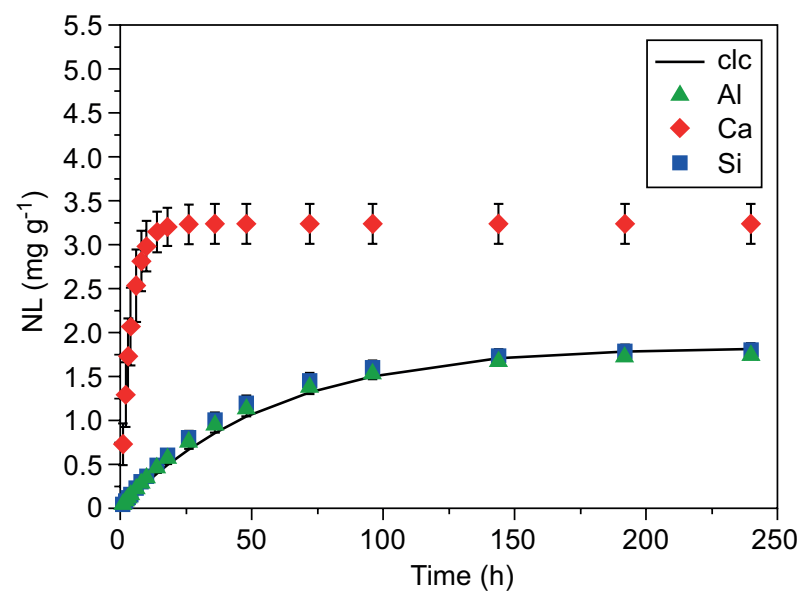

Figure 4. Static leaching test in coolant solution at $70{ }^{\circ} \mathrm{C}$ (points - experimental values with error bars, line - calculated $N L$ values). 
$A=(12.10 \pm 0.11), B=(3541 \pm 39)$. The values of the rate constant, $k$, and of the formal solubility product, $K$, evaluated at each temperature are summarized in Table 2. The comparison of experimental and calculated $N L$ values is presented in Figure 1 for the temperature $90{ }^{\circ} \mathrm{C}$ and in Figure 2 for the temperature of $70^{\circ} \mathrm{C}$. In both cases the acceptable coincidence of experimental points with the calculated $N L$ values can be found for $\mathrm{Al}$, $\mathrm{B}$, and $\mathrm{Si}$. The $N L$ values of calcium are higher due to the diffusion leaching of $\mathrm{Ca}^{2+}$ ions from glass. This effect is pronounced for the lower temperature, where the glass dissolution is slow.

In the second step the proposed semiempirical kinetic equation was qualified by the analysis of the glass grains leaching in coolant solution. By minimization of the sum of squares (Equation 9) following estimates of optimized parameters were obtained: $a=(19.32 \pm 0.19)$, $b=(7820 \pm 66), A=(12.60 \pm 0.07), B=(3618 \pm 26)$. It can be seen that obtained values of $A$ and $B$ parameters are almost the same like in the case of leaching in distilled water. On the other hand the $a$ and $b$ parameters differ significantly from the leaching in distilled water. The reason is in $\mathrm{pH}$ dependence that is implicitly contained in the rate constant $k$. The coolant solution buffers the $\mathrm{pH}$ value in the alkaline region. The values of the rate constant, $k$, and of the formal solubility product, $K$, evaluated at each temperature are summarized in Table 2. The alkaline character of the coolant solution resulted in the higher values of the rate constant $k$. The comparison of experimental and calculated $N L$ values is presented in Figure 3 for the temperature $90{ }^{\circ} \mathrm{C}$ and in Figure 4 for the temperature of $70{ }^{\circ} \mathrm{C}$. In both cases the perfect coincidence of experimental points with the calculated $N L$ values (within the experimental error) can be found for $\mathrm{Al}$, and $\mathrm{Si}$. The $N L$ values of calcium are much higher due to the diffusion leaching of $\mathrm{Ca}^{2+}$ ions from glass. Contrary to the leaching in distilled water, this effect is very high also at the temperature of $90{ }^{\circ} \mathrm{C}$. Some explanation can be found in high borate concentration in coolant solution. This enhances the driving force for calcium ions diffusion.

Table 2. Optimized values of the rate constant $k$ and formal solubility product $K$.

\begin{tabular}{lclcc}
\hline $\begin{array}{l}\text { Leaching } \\
\text { medium }\end{array}$ & Temp. & \multicolumn{1}{c}{$90{ }^{\circ} \mathrm{C}$} & $80{ }^{\circ} \mathrm{C}$ & $70{ }^{\circ} \mathrm{C}$ \\
\hline \multirow{2}{*}{ Water } & $k$ & $0.062 \pm 0.019$ & $0.029 \pm 0.009$ & $0.013 \pm 0.004$ \\
& $K$ & $10.42 \pm 1.61$ & $7.91 \pm 1.24$ & $5.91 \pm 0.94$ \\
\hline \multirow{2}{*}{ Coolant } & $k$ & $0.109 \pm 0,028$ & $0,059 \pm 0,016$ & $0.031 \pm 0,008$ \\
& $K$ & $13.96 \pm 1.43$ & $10.53 \pm 1.10$ & $7.81 \pm 0.83$ \\
\hline
\end{tabular}

\section{CONCLUSIONS}

It can be concluded that proposed semiempirical kinetic model allows the evaluation of the leaching kinetics for an arbitrary time-temperature schedule pro- posed for the LOCA scenario. Due to its semiempirical character its parameterization is needed for each particular leaching solution.

\section{Acknowledgement}

This work was supported by the Slovak Grant Agency for Science under the grants VEGA 1/0064/18 and VEGA 2/0088/16, and by the project ZDESJE, ITMS code 26220220084, of the Operational Program Research and Development funded from the European Fund of Regional Development.

\section{REFERENCES}

1. Zigler G., Beaty R., Brideau J., Comes L., Rao D.V., Ruiz N., Sciacca F., Sharrer C., Thomas W., Walsh R. (1994): Parametric study of the potential for BWR ECCS strainer blockage due to LOCA generated debris. NUREG/CR-6224 SEA No. 93-554-06-A:1.

2. Rao D.V., Shaffer C.J., Leonard M.T., Ross K.W. (2003): Knowledge base for the effect of debris on PWR ECCS performance. NUREG/CR-6808 LA-UR-03-0880.

3. Park J.H., Kasza K., Fisher B., Oras J., Natesan K., Shack W.J. (2006): Chemical Effects Head - Loss Research in Support of Generic Safety. NUREG/CR-6913 ANL-06/41, Issue 191.

4. Soltész V., Vicena I., Liška M., Galusková D., Mattei J.M. (2012): Corrosion of Bourre glass fibers in borate water solution. Glass Technology-European Journal of Glass Science and Technology Part A, 53, 139-145.

5. Soltesz V., Vicena I., Chromčíková M., Liška M., Mattei J.M. (2008): Chemical durability of glass thermal insulation fibers in borate and phosphate water solutions. Advance in Materials Research, 39-40, 363-366. doi: 10.4028/www.scientific.net/ AMR.39-40.363

6. Rouaix S., Cantrel L., Armand Y., Mattei J.M., Liška M., Galusková D., Vicena I., Soltesz V. (2008): Precipitate formation contributing to sump screens clogging of a nuclear power plant during an accident. Chemical Engineering Research and Design, 86, 633-639. doi: 10.1016/j.cherd.2008.03.016

7. Soltész V., Liška M., Chromčíková M., Faturíková K., Vlčková P., Kaňková H. (2011): Kinetics of static leaching tests of glass fiber insulation - coolant system. Sklář a keramik, 61, 172-175.

8. Chromčíková M., Vokelová J., Michálková J., Liška M., Macháček J., Gedeon O., Soltész V. (2016): Chemical durability of gamma-irradiated glass fibrous insulation. Nuclear Technology, 193, 297-305. Doi: 10.13182/NT15-22

9. Helebrant A. (1997): Kinetics of corrosion of silicate glasses in aqueous solutions. Ceramics-Silikáty, 41, 147-151.

10. Helebrant A., Matoušek J. (1998): Mathematical Models of Glass Interaction with Water and Aqueous Solutions. Silikáty, 32, 173-182.

11. Aagaard P., Helgeson H.C. (1982): Thermodynamic and kinetic constraints on reaction rates among minerals and aqueous solutions. I. Theoretical considerations. American Journal of Science, 282, 237-285.

12. Krauklis A.E., Gagani A.I., Vegere K., Kalnina I., Klavins M., Echtermeyer A.T. (2019): Dissolution Kinetics of R-Glass Fibers: Influence of Water Acidity, Temperature, and Stress Corrosion. Fibers, 7, 22-40. Doi: 10.3390/fib7030022

13. Gin S., Jégou Ch., Frugier P., Minet Y. (2008): Theoretical consideration on the application of the Aagaard-Helgeson rate law to the dissolution of silicate minerals and glasses. Chemical Geology, 255, 14-24. Doi: 10.1016/j.chemgeo.2008.05.004

14. Jones R. L., Betz D. (2004): The kinetics of corrosion of E-glass fibres in hydrochloric acid. Journal of Materials Science, 39, 5633-5637. Doi: 10.1023/B:JMSC.0000040069.00158.01 